\title{
Da sociedade ao indivíduo e de volta à sociedade: socialização e individuação em G. H. Mead
}

\section{From society to the individual, and back to society: socialization and individuation in G. H. Mead}

De la sociedad al individuo, y de vuelta a la sociedad: socialización e individuación en G. H. Mead

Cledes Antonio Casagrande*

\section{Resumo}

\begin{abstract}
Este ensaio tem por tema central os processos de socialização e de individuação em George Herbert Mead. Tratase de um texto teórico e hermenêutico, com fins propedêuticos, ligado ao campo da filosofia da educação. $O$ objetivo consiste em discutir como Mead, em seus escritos, compreende e descreve os processos de formação dos sujeitos sociais e quais as possíveis correlações desses processos com a capacidade de viver em comunidade, sob a égide da ética e da democracia. No texto, argumenta-se que o processo de formação do self remete à socialização individuadora e que a emergência da consciência do "si mesmo" somente é possível por meio da interação e da participação efetiva na vida da comunidade. Por isso, é possível ponderar que a incapacidade de pensar e agir desde uma perspectiva social representa um déficit formativo, de reponsabilidade do próprio indivíduo e também da sociedade.
\end{abstract}

Palavras-chave: educação; socialização; individuação; ética; democracia.

\section{Abstract}

This essay has as its central theme the processes of socialization and individuation in George Herbert Mead. It is a theoretical and hermeneutic text, with propaedeutic purposes, linked to the field of philosophy of education. The objective is to discuss how Mead, in his writings, understands and describes the processes of formation of social subjects and what are the possible correlations of these processes with the ability to live in community, under the aegis of ethics and democracy. In the text, it is argued that the process of forming the self refers to individuating socialization, and that the emergence of the self is only possible through interaction and the effective participation in the life of the community. Therefore, it is possible to consider that the inability to think and act from a social perspective represents a formation's deficit, which is liability the individual himself and also of the society.

Keywords: education; socialization; individuation; ethics; democracy.

Recebido em: 14/07/2020 Aprovado em: 13/01/2021

http://dx.doi.org/10.5335/rep.v28i1.11232

Doutor em Educação pela Pontifícia Universidade Católica do Rio Grande do Sul. Docente e pesquisador no Programa de Pós-Graduação em Educação da Universidade La Salle; Pró-Reitor Acadêmico e Vice-Reitor dessa mesma instituição. Orcid: https://orcid.org/0000-0003-1499-1661.E-mail: cledescasagrande@gmail.com 


\section{Resumen}

Este ensayo tiene como tema central los procesos de socialización e individuación en George Herbert Mead. Es un texto teórico y hermenéutico, con fines propedéuticos, vinculado al campo de la filosofía de la educación. El objetivo es discutir cómo Mead, en sus escritos, comprende y describe los procesos de formación de los sujetos sociales y cuáles son las posibles correlaciones de estos procesos con la capacidad de vivir en comunidad, bajo los principios de la ética y la democracia. En el texto, se argumenta que el proceso de formación del yo se refiere a la socialización individualizada, y que el surgimiento de la conciencia del "yo" solo es posible a través de la interacción y la participación efectiva en la vida de la comunidad. Por lo tanto, es posible considerar que la incapacidad para pensar y actuar desde una perspectiva social representa un déficit formativo, que es responsabilidad del individuo y también de la sociedad.

Palabras clave: educación; socialización; individuación; ética; democracia.

\section{Introdução}

"The man without a generous impulse is abnormal and abhorrent" (MEAD, 1981, p. 392).

Mead é um autor clássico e seminal para entender os processos de formação dos sujeitos sociais, especialmente o conceito de individuação por meio da socialização ${ }^{2}$. A diminuta difusão de seus escritos no cenário acadêmico brasileiro e a existência, entre nós, de certa crítica velada ao pragmatismo relegaram-lhe uma posição de autor secundário, somente recentemente redescoberto e tematizado ${ }^{3}$.

Entretanto, isso não significa que sua originalidade e sua concepção diferenciada da formação do self, da ética e da democracia tenham menor valor acadêmico. Habermas (2010, p. 213), por exemplo, ao referir-se à importância deste autor, afirma: "Na psicologia social de G. H. Mead, vejo esboçada a única tentativa com perspectiva de êxito para reproduzir no plano conceitual o pleno teor significante da individuação". Honneth (2003, p. 125) alinha-se no elogio à teoria intersubjetiva de Mead com a seguinte assertiva:

Em nenhuma outra teoria, a ideia de que os sujeitos humanos devem sua identidade à experiência de um reconhecimento intersubjetivo foi desenvolvida de maneira tão consequente sob os pressupostos conceituais naturalistas como na psicologia social de George Herbert Mead.

Tugendhat (1993), por seu turno, atribui a Mead posição de destaque no que tange à possibilidade de entender os processos da autoconsciência e da autodeterminação dos sujeitos. Entre nós, Dalbosco (2010) foi um dos primeiros a reconhecer o potencial pedagógico do conceito pragmatista de ser humano advindo desse autor. 
Levando em consideração a relevância teórica e o aumento do interesse do público acadêmico em G. H. Mead, este ensaio objetiva abordar, de modo panorâmico, os processos de individuação por meio da socialização, uma das principais teses deste autor, bem como as possíveis implicações dessa tese para o campo da educação. O texto consiste em um exercício teórico-hermenêutico, com foco no campo da filosofia da educação, e parte das seguintes questões correlatas: Como G. H. Mead concebe o processo de formação do self? Que reflexões educacionais podem emergir da compreensão de Mead acerca da individuação por meio da socialização no atual contexto brasileiro? Quais as possíveis relações entre formação do eu e a vida em sociedade, na perspectiva apontada por este autor? Expresso de outro modo, interessa-nos discutir, aqui, como Mead, em seus escritos, compreende e descreve os processos de formação dos diversos sujeitos sociais e quais as possíveis correlações desse processo formativo com a capacidade de viver em comunidade, sob a égide da democracia e da ética ${ }^{4}$.

A matriz intersubjetiva e simbólica a partir da qual Mead concebe a formação dos indivíduos em sociedade, ou a individuação por meio da socialização, traz implicações lógicas para compreendermos o campo da educação e da formação humana. A principal delas pode ser resumida na seguinte asserção: a incapacidade de pensar e de agir socialmente, ou desde a perspectiva de uma sociedade mais ampla, antecipando as condições ideais de uma vida boa em comunidade, com a consequente superação do egoísmo e do egocentrismo, enseja uma espécie de déficit formativo e humano, de responsabilidade do próprio indivíduo e também da sociedade na qual está inserido ${ }^{5}$.

Tendo em vista o recorte temático proposto e a necessária reflexão acerca da assertiva anterior, estruturamos o artigo em três seções. Na primeira, num movimento que denominamos 'da sociedade ao indivíduo', apresentaremos como Mead descreve os processos de socialização e de individuação, ou os processos de formação do self. Importa destacar aqui o papel da interação, da linguagem e da comunicação para a estruturação da noção "si mesmo". Na sequência, na seção que denominamos 'e de volta à sociedade', explicitaremos o modo como um sujeito individuado pode contribuir, por meio do agir ético e político, com a reconstrução da própria sociedade. Finalmente, teceremos algumas considerações sobre a educação e os processos formativos atuais à luz dos elementos teóricos já explicitados. 


\section{Da sociedade ao indivíduo: uma leitura do processo de formação do self em G. H. Mead}

Os escritos de G. H. Mead demarcam um renovado posicionamento teórico em relação à compreensão dos processos de individuação dos sujeitos, deslocando-os definitivamente aos campos da intersubjetividade e da comunicação. Diferente da tradição filosófica vigente em sua época, Mead aponta que a gênese do self é social, pois o sujeito somente desenvolve uma noção si mesmo na relação com seu entorno, físico e social, por meio de processos de socialização, com a internalização das estruturas simbólicas da linguagem, numa matriz intersubjetiva e simbólica.

A radicalidade da afirmação da gênese social do self pode ser percebida na seguinte afirmação: "Devemos ser outros se quisermos ser nós mesmos" (MEAD, 1981, p. 292). Essa asserção inclui definitivamente o elemento social na estrutura do 'si mesmo' e enseja o reconhecimento que a socialização antecede a individuação, mas não a elimina, pois indivíduo e sociedade constituem-se e evoluem num processo de mútua dependência.

O caráter estruturante do self encontra-se no processo de interação simbólica mediante o qual um organismo reage ao gesto do outro, internalizando a atitude ou o papel social deste outro, o que pressupõe a interdependência entre os diversos sujeitos sociais. A concepção de que o self estrutura-se e se desenvolve a partir de uma matriz social e simbólica sustenta-se em duas razões fundamentais: a) o reconhecimento do caráter social da vida humana, a anterioridade da sociedade em relação ao indivíduo e a interdependência entre o sujeito e a sociedade; b) a centralidade da comunicação simbólica enquanto o elemento responsável pela estruturação do self, e a evolução da comunidade humana, como veremos na sequência.

\section{a) O caráter social da vida humana}

Como já apontamos, a obra de Mead pode ser compreendida como uma grande defesa da tese de que a individuação ocorre, necessariamente, por meio da socialização. Isso implica dizer que a vida humana, em todas as suas fases, organiza-se e desenvolve-se a partir da dimensão social, especialmente pela imersão dos indivíduos em uma comunidade concreta, e das consequentes aprendizagens neste contexto. Ou seja, a gênese do self é social porque o ser humano humaniza-se e individualiza-se por meio de processos de socialização.

Mead destaca o caráter originalmente social da vida humana, divergindo das tradições filosóficas da sua época e enfatizando que as estruturas da sociedade antecedem as estruturas subjetivas do indivíduo. 
Desenvolveu-se uma teoria que as sociedades humanas surgiram dos indivíduos, não os indivíduos da sociedade. Desta maneira, a teoria do contrato social afirma que os indivíduos existem primeiramente como indivíduos inteligentes, como pessoas (as selves), e que estes indivíduos reúnem-se e formam sociedade. [...]. Contudo, se a posição que eu refiro está correta, se o indivíduo obtém seu self somente através da comunicação com outros, somente através da elaboração de processos sociais mediante a comunicação significante, então o self não pode preceder o organismo social. O último deve existir primeiro (MEAD, 1967, p. 233).

Como vemos na citação anterior, a vida em sociedade antecede e é condição para a formação do indivíduo, e a comunicação possui um papel central para a socialização e a individuação.

Em Mind, Self and Society, Mead (1967) recorre à analogia entre as sociedades humanas e as sociedades animais com a intenção de demonstrar o caráter social da vida. No ambiente natural, podemos constatar que todas as formas sociais de vida, inclusive aquelas de animais inferiores, ou não humanos, estão pautadas em relações sociais. Por isso, "não há organismo vivo, de qualquer espécie, cuja natureza ou constituição seja tal que possa existir ou manter-se em completo isolamento de todos os demais organismos vivos" (MEAD, 1967, p. 228).

Animais como a formiga e a abelha, embora manifestem condutas sociais, e vivam em sociedades organizadas e hierarquizadas, não fundamentam seus comportamentos numa estrutura simbólica de interação. Nos animais inferiores não humanos, ocorre uma diferenciação fisiológica que define as funções de cada um na conduta social. O que diferencia e caracteriza os seres humanos é a comunicação, pois "a sociedade humana depende do desenvolvimento da linguagem para sua forma distintiva de organização" (MEAD, 1967, p. 235). Desse modo, não podemos considerar que os atos de uma formiga ou de uma abelha sejam atos sociais no sentido estrito do termo, pois um ato, para ser considerado social, necessita estar orientado ao outro de modo intencional, pressupondo a interação comunicativa e a cooperação entre os diversos indivíduos (MEAD, 1981).

Diferente dos outros animais, é por meio da comunicação simbólica que o ser humano desenvolve a capacidade de adaptar o próprio comportamento ao comportamento do outro.

O self, que é central para toda a chamada experiência mental, aparece somente na conduta social dos vertebrados humanos. Os indivíduos se convertem em um objeto para si mesmos, precisamente, porque descobrem-se a si mesmos adotando a atitude dos outros que estão envolvidos nas suas condutas. [...] Além do mais, a verdade é que o self pode existir somente para o indivíduo se ele assume os papéis sociais dos outros (MEAD, 1981, p. 283-284). 
A experiência de ser um self, um 'si mesmo', somente pode ser atingida no envolvimento e na interação com os outros. Por isso, Biesta (1998, p. 74) constata que, para Mead, "a intersubjetividade precede a subjetividade sendo constitutiva dela”. Isso nos leva a entender que a autoconsciência dos diversos sujeitos consiste numa construção intersubjetiva e simbólica. Intersubjetiva porque o indivíduo se constitui no recurso à sociedade; e simbólica porque implica construção de sentido e de significados por meio da linguagem. Tal construção não é isolada no tempo e no espaço. Ela emerge no quadro determinado das ações e das relações do indivíduo com os outros e com o meio ambiente em que vive.

Kaminsky (2009, p. 12) entende que a compreensão do processo de subjetivação presente em Mead inova em relação àquelas até então vigentes, porque sua teoria do sujeito enseja uma ruptura com qualquer tipo de essencialismo e uma aposta em um "perspectivismo fundado em uma ontologia da pluralidade: si mesmo posto em diálogo, enlace e tensão autoconsciente pela via do outro generalizado".

Honneth (2009) reconhece que a interpretação de Mead acerca da subjetivação via interação social continua válida. Entende que na psicologia social de Mead estão esboçados os primeiros elementos de uma compreensão que identifica a linguagem, a comunicação e a interação como marcos na aquisição de uma identidade pessoal.

Para Mead não resta dúvida de que o sujeito individual não pode adquirir uma identidade consciente a não ser desde uma transposição a uma perspectiva excêntrica, de um outro representado de maneira simbólica, desde a qual aprende a olhar a si mesmo e ao seu atuar como participante de interação (HONNETH, 2009, p. 283).

A consciência de si mesmo emerge de um processo de reflexibilidade, de antecipação e de reação à atitude do outro. Esse processo é, inicialmente, gestual, progredindo, posteriormente, para uma estruturação simbólica mediante a interação social. De acordo com Biesta (1998, p. 83), "o gesto, tal como Mead o compreende, consiste na primeira fase no ato social". A ação ou gesto de um indivíduo é estímulo para a reação ou resposta do outro.

A contribuição de Mead, consiste, portanto, na afirmação de que a subjetividade e a consciência são produtos da intersubjetividade e da interação social. Há, em seus escritos, o reconhecimento de que nós somos inscritos numa matriz intersubjetiva, numa espécie de rede de relações e de interações a partir da qual emerge a consciência, a identidade individual e a sociedade.

Importa destacar que sob a perspectiva do princípio evolutivo, o indivíduo e a sociedade são coparticipes e interdependentes de um mesmo processo. 
As modificações que introduzimos na ordem social na qual nos encontramos envolvidos, implicam necessariamente que introduzamos modificações em nós mesmos. [...]. Assim, as relações entre a reconstrução social e a reconstrução do self ou da personalidade são recíprocas e internas ou orgânicas. [...]. Ou em poucas palavras, a reconstrução social e a reconstrução do self ou da personalidade são os dois aspectos de um processo somente: o processo da evolução social humana (MEAD, 1967, p. 309).

O processo evolutivo, que engloba self e sociedade, por meio da individuação e da socialização, tensionando a formação de um si mesmo e a melhoria constante da vida da comunidade, é, simultaneamente, ontogenético e filogenético. Ou seja, pela interação e comunicação entre os diferentes sujeitos que vivem em comunidade formam-se as estruturas da personalidade e, ao mesmo tempo, as estruturas intersubjetivas de coordenação da sociedade.

A sociedade constitui-se não pela simples soma dos diversos indivíduos que dela participam ou que a constituem. Ela consiste, sobremaneira, no conjunto das ações de seus membros, ações intencionadas e organicamente estruturadas. No pragmatismo de Mead, o que conta é a ação realizada, a vinculação efetiva a um projeto comum e a implicação concreta de cada um com o todo da comunidade. $\mathrm{Ou}$ seja, o ser humano realiza-se na medida de sua participação efetiva no seio da comunidade. A participação no todo social é que distingue o grau de socialização e o nível de individuação de cada sujeito. Quanto mais implicado na sociedade, mais se socializa, mais se individualiza e mais adquire um self, uma consciência de si como um 'si mesmo', pois estará adquirindo a capacidade de olhar o todo desde uma perspectiva social e, ao mesmo tempo, evoluirá enquanto um ser individuado, descentrando as próprias perspectivas.

\section{b) Linguagem, comunicação simbólica e estrutura do self}

Mead aponta que o caráter estruturante do self encontra-se na linguagem, mais precisamente no processo de interação simbólica entre os diversos sujeitos sociais, por meio da qual um organismo reage ao gesto do outro, internalizando a atitude ou o papel social deste outro. Nesse sentido, ele afirma:

As sociedades humanas nas quais estamos interessados são sociedades de selves. O indivíduo humano é um self somente na medida em que toma a atitude do outro em direção a si mesmo. Na medida em que essa atitude é a de certo número de outros, e na medida em que ele pode assumir a atitude organizada de um número de participantes na atividade comum, ele assume as atitudes do grupo para si mesmo e, ao assumir esta ou estas atitudes, define o objeto do grupo, aquilo que define e controla a resposta (MEAD, 1981, p. 290). 
Como mencionado, o mecanismo empregado no processo de subjetivação é o da internalização da atitude do outro. Por isso,

As pessoas somente podem existir em relações definidas com outras pessoas. [...]. O indivíduo possui um self somente em relação com os selves dos outros membros do seu grupo social; e a estrutura de seu self expressa ou reflete a pauta geral de comportamento do grupo social ao qual pertence, assim como o faz a estrutura do self de todos os demais indivíduos pertencentes a esse grupo social (MEAD, 1967, p. 164).

Mead (1981, p. 284) apresenta duas ilustrações do processo de desenvolvimento do self: "o primeiro estágio é o do brincar (play) e o segundo o do jogar (game), que são distintos entre si”. O brincar e o jogar consistem em analogias dos fatores básicos implicados na gênese do self no decorrer da infância, e demonstram a estruturação da noção de "outro generalizado", uma convenção universalizada da vontade coletiva da comunidade, que necessita ser internalizada por parte do indivíduo para que ele desenvolva uma noção de "si mesmo".

Ao brincar, a criança adota vários papéis, um depois do outro, de pessoas ou animais, que estão presentes em sua vida, e que possibilita-lhe transcender a barreira do próprio ego, em direção a uma organização de atividades sociais, nas quais a centralidade em si mesma começa a ser rompida pela emergência de uma noção de um "outro" e de um "nós". Nesse sentido, exemplifica Mead (1967, p. 150-151):

A criança brinca de ser uma mãe, um professor, um policial; ou seja, como dizemos, adota diferentes papéis. [...]. Por exemplo, brinca que está oferecendo algo e o compra; entrega uma carta e a recebe; dirige-se a si mesmo como um dos pais, como um professor; prende-se como um policial. Tem uma série de estímulos que provocam nele a classe de reações que provocam em outros. Toma esse grupo de reações e as organiza em certo todo. Tal é a forma mais simples de ser outro para o próprio self.

Esse brincar livre, sem regras aparentes, possibilita a organização de uma estrutura de conversação interior e o início do processo de diferenciação de papéis sociais.

O jogar (game), por sua vez, refere-se às atividades com regras e pressupõe a participação de mais de um jogador. Ao participar de um jogo coletivo, a criança aprende a organizar o próprio comportamento adequando-o ao comportamento dos outros jogadores, de modo que a atividade seja estratégica e articulada. O jogador necessita adotar o papel que lhe é peculiar no jogo e, ao mesmo tempo, ser capaz de modificar ou trocar de papéis no decorrer da atividade, de modo que seja capaz de antecipar os possíveis movimentos ou ações dos companheiros com fins de obter êxito ou, mesmo, antecipar as jogadas e os papéis dos adversários, impedindo-os de vencer. Isso será possível mediante a internalização das expectativas de ação e, 
ao mesmo tempo, da organização dessas expectativas de modo que possa intervir adequadamente no transcorrer do jogo.

O jogar, em equipe, configura um avanço em relação ao brincar individual, pois amplia o horizonte da participação, da cooperação social e do descentramento de si por parte dos envolvidos. Representa, também, uma situação arquetípica do desenvolvimento da consciência de si, uma vez que articula a assunção de papéis sociais, a vivência das regras convencionais da sociedade e a necessidade de um controle pessoal do comportamento, com vistas à consecução de uma atividade que envolve cooperação e participação com outros membros da comunidade.

No jogo, temos a introdução de um "outro" convencional no processo; não se trata de um novo indivíduo, mas uma organização de atitudes e de ações supraindividuais que envolvem todos os competidores no mesmo processo. Com a internalização da figura desse "outro", forma-se, mediante processo de universalização, o que Mead denomina de "o outro generalizado".

Pois em um jogo (game) há um procedimento regulado e normas. A criança deve adotar não somente o papel do outro, como ela faz no brincar, mas deve assumir os vários papéis de todos os participantes do jogo e governar suas ações de acordo com isso. [...]. E essas reações organizadas se convertem no que denominamos de "outro generalizado" (generalized other), que acompanha e controla sua conduta. A presença desse outro generalizado em sua experiência é o que proporciona um self para si (MEAD, 1981, p. 285).

O "outro generalizado" condensa a vontade coletiva expressa em termos de valores, regras, convenções, leis e costumes vigentes na comunidade. Trata-se da dimensão social que necessita ser internalizada e que intervém nas atitudes dos indivíduos distintos. Por isso, para Mead (1967, p. 154), "a atitude do outro generalizado é a atitude de toda a comunidade". A adoção do "outro generalizado" por parte do indivíduo consiste numa precondição ao desenvolvimento do self.

Somente na medida em que ele adotar as atitudes do grupo social organizado, ao qual pertence, em direção à atividade social organizada e cooperativa, ou direcionada à série de atividades na qual esse grupo está ocupado, somente nessa medida ele desenvolverá um self pleno ou possuirá o tipo de self pleno que desenvolveu (MEAD, 1967, p. 155).

A necessidade de participação e de cooperação no grupo social, ou seja, a premência do processo de socialização ao de individuação consiste, também, no modo mediante o qual a sociedade exerce controle sobre seus membros. E esse controle social "dependerá do grau que o indivíduo assumir as atitudes daqueles no grupo que estão envolvidos com ele em suas atividades sociais” (MEAD, 1981, p. 290). Ou seja, não basta ao indivíduo estar num espaço geográfico definido; é necessário que 
viva como um membro de um grupo determinado, que se inculture, que assuma os valores, as crenças e os objetivos próprios da comunidade à qual pertence.

Apesar do acento dado à dimensão social no processo de individuação, Mead entende que também existe uma estrutura subjetiva própria, não redutível à pressão do grupo social. Nesse sentido, ele afirma:

Certamente não somos somente o que é comum a todos: cada uma das pessoas é distinta de todas as demais; porém é preciso que exista uma estrutura comum como a que esboçamos a fim de que possamos ser membros de uma comunidade. Não podemos ser nós mesmos a menos que sejamos também membros numa comunidade de atitudes que controla as atitudes de todos (MEAD, 1967, p. 163-164).

Mead reconhece a existência de uma instância reflexiva do sujeito, uma base subjetiva no self que é irredutível às determinações do grupo social. Expresso de outro modo, para que o indivíduo humano desenvolva uma consciência de "si mesmo", um self, é premente que, num processo de reflexibilidade, ele coloque a si mesmo enquanto objeto. Para detalhar esse processo, Mead recorre a uma bipartição do self, diferenciando o "eu" ( $I$ ) do "me/mim" ( $m e$ ) e, ao mesmo tempo, explicitando a dinâmica dialética que se instala no interior da consciência de "si mesmo". Nessa dinâmica, "o 'eu' (I) reage ao self, que se originou por meio da adoção das atitudes dos outros" (MEAD, 1967, p. 174).

Mead entende que o que pode ser elevado à consciência é o "mim" (me). Como vimos, a consciência de si originou-se da internalização das atitudes dos outros, especialmente da assunção da perspectiva generalizada do grupo social, ou do "outro generalizado". O "eu" (I), entretanto, enquanto dimensão pessoal, não é redutível ao "outro generalizado" internalizado enquanto "mim", nem passível de captura pela consciência.

O 'eu' (I) é a reação do organismo às atitudes dos outros; o 'mim' (me) consiste na série organizada de atitudes dos outros que cada um assume. As atitudes dos outros constituem o 'mim' organizado e, logo, um reage frente a elas como um 'eu' (MEAD, 1967, p. 175).

O "eu" (I) consiste na dimensão não previsível do self, no elemento que nos identifica enquanto únicos e singulares, que não é dado diretamente na experiência, apenas perceptível a posteriori. Ele não pode ser objeto da consciência, pois emerge da ação do indivíduo em uma situação social determinada. Trata-se da novidade do momento, do ineditismo da reação ao dado, com uma orientação a um futuro indefinido. Ou seja, ele é uma reação que não pode ser prevista, tampouco antecipada.

O "mim" (me) é consciente, visto sua existência imediata para o indivíduo em sua consciência. $\mathrm{O}$ "mim" permite, enquanto consciência de si mesmo, a convivência 
social segundo os padrões sociais estabelecidos, pois possui todas as atitudes generalizadas dos outros. É a dimensão que mantém a estabilidade das ações e reações do self, pois está pautada nas convenções do todo social: o "mim" é convencional.

O 'eu' (I), pois, nessa relação entre o 'eu' $(I)$ e o 'mim' (me), é algo que, por assim dizer, responde a uma situação social que se encontra dentro da experiência do indivíduo. É a resposta que $o$ indivíduo tem às atitudes que outros adotam em direção a ele, quando ele adota uma atitude em relação a eles. Assim sendo, as atitudes que ele adota em relação a eles estão presentes em sua própria experiência, porém sua resposta a elas conterá um elemento de novidade. O 'eu' (I) proporciona a sensação de liberdade, de iniciativa (MEAD, 1967, p. 177).

A ação ou reação de alguém a algum acontecimento ou fato não pode ser prevista. Isso significa que a reação exata, a maneira específica que reagiremos, diante de uma determinada situação somente pode ser evidenciada depois de sua consecução. Somente depois do ato concretizado e da sua consequente apreensão pela memória é que poderemos ter noção exata do realizado. Sendo o "eu" $(I)$ completamente $a$ posteriori e consequência das ações e reações do self como um todo, teremos condições de criar uma imagem pessoal somente mediante a conduta social, ao agirmos e reagirmos em contextos sociais.

No self, perceptível no agir e reagir dos diversos sujeitos, o "eu" e o "mim" aparecem de formas distintas, mas mutuamente dependentes.

Não existiria um 'eu' $(I)$, no sentido em que usamos esse termo, se não houvesse um 'mim' (me); não haveria um 'mim' sem uma reação na forma do 'eu'. Os dois, tal como aparecem em nossa experiência, constituem a personalidade. Somos indivíduos nascidos em certa nacionalidade, localizados em certo ponto geográfico, com tais relações familiares e tais relações políticas. Tudo isso representa certa situação que constitui o 'mim'; porém, isso envolve, necessariamente, uma ação contínua do organismo em direção ao 'mim' dentro do processo no qual reside (MEAD, 1967, p. 182).

Por meio da contraposição dialética do 'eu' e do 'mim', Mead procura balancear a relevância das dimensões social e subjetiva no processo de estruturação da personalidade, entendida enquanto self ou noção de 'si mesmo'. Com isso também resguarda a possibilidade da novidade, da criação e recriação de si mesmo e da comunidade e, ao mesmo tempo, exclui qualquer tendência ao determinismo social, como veremos na sequência.

\section{E de volta à sociedade: comentários sobre ética, democracia e reconstrução social}

A formação do self, na perspectiva apontada por Mead, correlaciona-se à evolução e à reconstrução da vida em comunidade ${ }^{7}$. Por isso, podemos dizer que existe 
um movimento formativo de mão dupla: da sociedade ao indivíduo, e de volta à sociedade. Ou seja, quanto mais um indivíduo progride no processo de tornar-se um self, quanto mais adquire capacidade de agir reflexivamente e de descentrar o seu ponto de vista, de uma perspectiva egoísta para um olhar mais comunitário, tanto mais estará apto a participar do processo de reconstrução do todo social, no qual ele é formado e do qual participa ativamente. Aqui entra em cena o tensionamento entre formação do self em uma comunidade, com o necessário desenvolvimento de competências científicas e éticas, e a efetiva participação democrática, com a consequente reconstrução da própria sociedade, como veremos na sequência.

O processo de socialização individuadora implica sujeito e sociedade. Por meio da interação simbólica entre os indivíduos de uma comunidade formam-se, respectivamente, as estruturas da personalidade e, ao mesmo tempo, as estruturas de coordenação daquela mesma sociedade. A partir dessa constatação, podemos afirmar que:

O grau de desenvolvimento do self depende, então, da amplitude das atitudes comuns que permitam uma determinada organização social; porém também a organização plena da sociedade humana - sua efetiva vigência - depende completamente de sujeitos que possam orientar suas condutas e fundar suas consciências, suas autoestimas, na função que exercem dentro da 'sociedade organizada' (YNCERA, 1994, p. 332).

O ser humano somente pode desenvolver o self num contexto comunitário e de interação simbólica, ao mesmo tempo em que se dedica às causas da comunidade. Ao participar ativamente da vida comunitária, mediante efetiva cooperação e envolvimento nas questões que são centrais à organização dela, terá a possibilidade de influenciar nos seus rumos. Trata-se de um processo de mão dupla: o indivíduo, mediante a participação e a cooperação na vida social, converte-se em um self e, ao mesmo tempo, pode contribuir na reconstrução da vida da comunidade. Neste sentido, e para compreender o que propõe Mead, precisamos considerar a implicação dos conceitos de 'outro generalizado' e a bipartição do self em 'mim' (me) e 'eu' (I), como mencionados anteriormente. Por isso, retomamos uma citação de Mead (1967, p. 196):

Frente ao 'mim' (me) está o 'eu' $(I)$. O indivíduo não tem somente direitos, mas também deveres; ele não é somente um cidadão, um membro da comunidade, mas ele é também alguém que reage à dita comunidade, e sua reação a ela, como temos visto na conversação de gestos, modifica-a. O 'eu' (I) é a resposta do indivíduo à atitude da comunidade, tal como dita atitude aparece em sua própria experiência. Sua reação a essa atitude organizada, por sua vez, modifica a comunidade.

O processo socializatório e a vida em sociedade supõem que possamos agir desde a perspectiva dos valores, costumes e regras aprendidos e internalizados - 
aquilo que constitui a noção de 'mim' (me). Ao mesmo tempo, pressupõe que cada um tenha a capacidade de agir enquanto um 'eu' $(I)$ - dimensão do agir que não pode ser prevista, visto tratar-se da resposta específica do sujeito em cada situação particular. Além disso, afirmar-se como um self, agindo enquanto um ser humano socializado e membro de uma comunidade, denota colocar em prática um rol de expectativas específicas na resolução de problemas que surgem, especialmente ter conduta racional, atuando sob os princípios do método científico, da ética e da participação democrática.

É necessário esclarecer que não existe, para Mead, uma oposição entre o uso do método científico, a capacidade de resolução de problemas, o processo de julgamento moral e a participação política e democrática (SILVA, 2009). Na base dessa afirmação repousa a premissa pragmática de que não se pode separar pensamento e ação. Nesse sentido, Reck (1981, p. 32) afirma: "Como um pragmatista devotado à tarefa da reconstrução social, Mead, tal qual Dewey, recomendou a aplicação do método científico aos problemas do homem, os conflitos sociais e os valores morais". Mead (1981) reafirma a importância do método científico, da aprendizagem e do uso do mesmo na resolução de problemas, relacionando-o com o desenvolvimento da própria inteligência ou razão, visto tratar-se de algo inerente à condição humana e necessário à evolução dos indivíduos e da sociedade.

O que se espera de um indivíduo com níveis superiores de integração e de desenvolvimento pessoal é que possua uma conduta racional, "um tipo de conduta autorreferida e organizada em conexão com a atitude comum da comunidade global à qual pertence o sujeito" (YNCERA, 1994, p. 302). Esse tipo de conduta racional pode ser utilizado para resolver problemas, tanto no campo da ciência, quanto no campo da ética e da política.

Agir de modo ético significa, para Mead, ter o ideal democrático da vida em comum como horizonte da ação. Trata-se de um agir que esteja alinhado às necessidades do grupo social e que o auxilie a encontrar as soluções mais adequadas aos problemas que se apresentam. Por isso, o agir ético pressupõe o uso do método da ciência para a solução dos problemas, o que principia com a consciência da interdependência social, a análise dos motivos que levam a ações específicas e ao discernimento da validade de cada um dos valores utilizados em cada situação.

A universalidade do agir prático alinha-se ao fato de nós, seres humanos, sermos capazes de assumir a atitude de qualquer outro ser humano. Diferente de Kant, que alocava a decisão moral na subjetividade, Mead (1967, p. 379) entende que o ponto de partida não está no indivíduo isolado, mas na sociedade: 
O homem é um ser racional porque é um ser social. [...] A sociabilidade concede a universalidade dos juízos éticos e compõe o fundamento da afirmação popular de que a voz de todos é a voz universal; ou seja, todos os que podem apreciar racionalmente a situação estão de acordo. A forma mesma de nosso juízo é, pois, social, de modo que o fim de ambos, conteúdo e forma, é um fim social.

Mead argumenta em prol da necessidade de que cada ato seja moral. Ou seja, em todo o processo do julgar ou do agir moral, será necessário levar em conta a intenção do agente, os impulsos e os valores conflitantes, bem como o fim almejado. Desse modo, uma ação será considerada moral quando forem esclarecidas as condições mediante as quais essa ação foi efetivada.

A norma ética do pragmatismo meadiano é, pois, um requerimento relativo à necessidade de que os impulsos de ação se convertam em motivos esclarecidos em função do conhecimento das condições concretas (intersubjetivas) nas quais as atividades hão de se expressar e das consequências prováveis de acarretará a atuação nessas condições (YNCERA, 1991, p. 156).

Os motivos das ações se encontram nos impulsos que levam à ação, os quais orientam os fins atribuídos às condutas. O principal critério para a deliberação moral consiste em sempre eleger os fins que reforçam os impulsos ou valores sociais. Ou seja, a orientação ou máxima moral será sempre o caráter social dos conteúdos em discussão.

Somente na medida em que alguém pode identificar com o bem comum seu próprio motivo e o fim que realmente persegue, somente nessa medida poderá chegar à meta moral e, assim, alcançar a felicidade moral. Assim como a natureza humana é essencialmente social em caráter, do mesmo modo os fins morais devem ser também sociais em sua natureza (MEAD, 1967, p. 385).

Com o reconhecimento de que nossa moralidade se coaduna com nossa natureza social, passamos a entender que os fins justificáveis, sob a perspectiva moral, ou os fins bons e desejáveis, são aqueles que conduzem à realização do ser humano enquanto um ser social. Isso ocorre porque "nossa moralidade se conecta à nossa conduta social. É como seres sociais que somos seres morais" (MEAD, 1967, p. 385). Estabelecer quais os valores adequados, quais as normas justificáveis e quais os modos de ação aceitáveis implica colocar como prova de aceitabilidade do juízo moral a consideração de todos os interesses envolvidos. Por isso:

Nos juízos morais temos que elaborar uma hipótese social e ninguém pode fazê-lo simplesmente desde seu próprio ponto de vista. Temos que olhar desde o ponto de vista de uma situação social. [...]. Agora, se perguntarmos qual é a melhor hipótese, a única resposta que podemos oferecer é que deve levar em conta todos os interesses que estão envolvidos (MEAD, 1967, p. 387). 
Em uma ação moral, o conteúdo que realmente prepondera enquanto impulso ou motivo deverá ser sempre aquele que reforça a pertença social e os impulsos comunitários. Ou seja, a orientação será sempre o caráter social dos conteúdos em discussão. Por isso, atuar tendo como referência 'todos os interesses envolvidos' constitui-se no pressuposto a partir do qual os sujeitos devem orientar suas ações e a avaliação moral de cada situação concreta. Como vemos, ultrapassar os próprios interesses é condição para que a pessoa evolua na capacidade de julgar e também de agir de acordo com motivos cada vez mais descentrados ou universais. Nesse sentido, agir para satisfazer somente os próprios impulsos e guiar-se por atitudes egoístas soam como características de uma pessoa limitada em seu processo formativo, alguém sem capacidade de descentramento e incapaz de olhar para além de si mesma.

O desenvolvimento individual e o progresso social ocorrem pelo combate dos impulsos e dos interesses individuais frente aos interesses sociais. É neste embate, de construção e reconstrução de hipóteses com vistas à resolução de problemas, de justificativas e de novas perspectivas entre indivíduo e sociedade, que se fundamenta a possibilidade de ambos evoluírem. A evolução de normas antigas para novas normas, mais adequadas à vida da comunidade, somente será possível pela "mediação de um novo tipo de indivíduo: alguém que se concebe a si mesmo como não se concebiam os indivíduos no passado" (MEAD, 1967, p. 386).

É importante destacar que a reação criativa do 'eu' ao estabelecido, o uso da razão e do método científico e a capacidade de descentramento constituem-se nos principais fundamentos que possibilitam a reconstrução e o progresso da estrutura social.

Uma pessoa pode chegar ao ponto de ir contra todo o mundo que a rodeia; ela pode levantar-se sozinha contra o mundo. Porém, para fazer isso, ela deve falar com a voz da razão para si mesma. Tem que abranger as vozes do passado e do futuro. Essa é a única forma na qual a pessoa pode ter uma voz que seja maior que a voz da comunidade. Geralmente supomos que essa voz geral da comunidade é idêntica à comunidade mais ampla do passado e do futuro; supomos que um costume organizado representa o que denominamos moralidade (MEAD, 1967, p. 168).

Para Mead, na condição de selves, ou indivíduos socializados, todos os sujeitos sociais têm o dever de auxiliar a comunidade à qual pertencem em seu progresso no tocante às leis, às regras e aos costumes. Isso será possível por meio da participação efetiva na comunidade e pelo interesse nas coisas comuns. E a chave para isso é a reflexão e o discurso, por meio dos quais será possível, inclusive, antecipar as condições ideais de uma vida boa para toda a comunidade. 
Portanto, estarão mais aptos a agir sob as premissas de fins universais e a participar ativamente na construção de uma sociedade melhor aqueles sujeitos que vivenciaram processo de individuação social e atingiram um maior grau de desenvolvimento qualitativo do self. Esses terão a capacidade de agir levando em conta os interesses de todos os envolvidos, contribuindo efetivamente para a evolução da comunidade.

\section{Considerações acerca das possíveis relações entre socialização, individuação e educação}

A teoria pragmática de Mead acerca da formação do self, especialmente a noção de individuação por meio da socialização, possui potencial para gerar reflexão e questionar os fundamentos dos processos educacionais atuais e futuros. Neste sentido, retomaremos duas abordagens que nos parecerem adequadas para a reflexão que estamos realizando: o potencial da noção de intersubjetividade radical, apontado por Biesta (1998, 1999a, 1999b) e por Biesta e Tröhler (2008); e a hipótese que norteou este texto - a responsabilidade social e individual do déficit formativo - buscando demonstrar algumas das possíveis conexões e implicações da mesma.

Biesta (1998, 1999a) reconhece na intersubjetividade radical e na interação, propostas por Mead, uma nova forma de compreensão e de fundamentação dos processos formativos, em substituição à tradição da filosofia da consciência. Ou seja, para Mead a educação necessita ser concebida como um processo social interativo, com base na ética e na efetiva participação na comunidade.

Para Biesta e Tröhler (2008, p. 08), "o que se torna claro com essa concepção social de educação é que Mead retorna, repetidas vezes, à situação social, à situação de cooperação e de coordenação social, como a matriz de toda educação". Por dimensão social da educação, ou situação social da educação, necessitamos entender que não se trata de uma referência simples aos dados sociais que interferem na constituição do self. Ou seja, a comunidade não é simplesmente mais um elemento interveniente, mas a condição fundamental da emergência do self. Disso decorre que não basta fazer parte de um grupo social, é necessário 'ser comunidade', sofrer o processo de socialização, encarnar os valores sociais e participar ativamente da vida da comunidade. Uma vez mais, vemos que o processo formativo não pode ser reduzido à referência de um sujeito solipsista, fechado em si mesmo, mas pressupõe um indivíduo aberto ao encontro com o outro, com o diverso, participante ativo da vida da comunidade e imerso no todo social. 
Além disso, se a educação é primariamente interação social, convivência e encontro, então a ética e a coordenação das ações sociais, ou o modo como os diversos sujeitos sociais interagem e organizam os modos de agir, passam a ser elementos incontestes para entender os processos formativos e os elementos constitutivos dos espaços e tempos educacionais. A imersão em um contexto social e o conviver com o outro implicam, necessariamente, a capacidade de julgamento moral, descentramento do eu e habilidade de cooperação para a resolução dos problemas que afetam o grupo social.

A concepção ética presente nos escritos de Mead articula-se e pressupõe formas concreta de socialização, de participação e de formação progressiva dos sujeitos sociais. Sujeito e sociedade são partes de um e mesmo processo de desenvolvimento, por isso fica evidente o caráter de interdependência e a necessidade de participação social de todos os envolvidos. Não se trata, como vimos, de uma participação formalista ou mesmo de um ideal ético vazio. A interdependência e a participação social são, antes disso, pré-requisitos práticos para o desenvolvimento da identidade e a melhoria da organização da própria comunidade.

Como apontamos no decorrer do texto, a matriz intersubjetiva e simbólica a partir da qual Mead concebe a formação dos indivíduos em sociedade traz implicações lógicas para pensarmos o campo da formação humana. Uma delas pode ser resumida na seguinte asserção: a incapacidade de pensar e de agir socialmente, ou desde a perspectiva de uma sociedade mais ampla, antecipando as condições ideais de uma vida boa em comunidade, com a consequente superação do egoísmo e do egocentrismo, denota uma espécie de déficit formativo e humano, de responsabilidade do próprio indivíduo e também da sociedade na qual está inserido.

Como vemos, compreender o processo de formação do self desde a perspectiva dos processos de socialização e de individuação leva-nos, necessariamente, a refletir e a questionar a efetividade dos processos formativos vivenciados pelos diversos sujeitos sociais, bem como dos pressupostos que fundamentam os mesmos. O déficit formativo, social e individual, se mostra mais claramente quando analisamos o contexto da sociedade brasileira, que parece, no atual momento, perdida na capacidade de autorregulação e também na proposição de processos formativos adequados aos novos membros.

O que desejamos enfatizar é que o atual cenário ético, político e educacional brasileiro leva-nos a questionar o resultado dos processos formativos que temos implementado em nossas instituições sociais, escolas e universidades. Em outros termos, todos os sujeitos envolvidos em desvios de recursos públicos, casos de cor- 
rupção, apropriação de bens públicos, proliferação de fakenews e intolerâncias, somente para citar algumas situações concretas que hoje são notícias nos canais de comunicação, passaram por escolas ou universidades. Ademais, é premente considerar que esses sujeitos sofreram processos de socialização e de individuação, tal qual Mead anunciou.

Isso nos leva, logicamente, a questionar se o arcabouço teórico de Mead mostra-se inadequado para analisar a nossa realidade ou, por outro lado, se os processos de socialização e de individuação não foram efetivos. Obviamente que toda a construção teórica possui seus limites explicativos, e aqui não queremos fazer uma defesa inconteste e acrítica do autor que tem orientado esse ensaio. Mas também podemos considerar que, em alguns casos da nossa sociedade brasileira, o processo socializatório formativo, escolar ou não, não está sendo efetivo, por déficits sociais, estruturais, mas também por escolhas dos próprios sujeitos, os quais não conseguem agir sob a perspectiva da ética e da ciência.

Vemos, portanto, que a responsabilidade pelos déficits formativos não pode recair somente sobre a sociedade e as instituições formativas. Como elencando anteriormente, uma das questões centrais que emerge da teoria ética de Mead consiste na capacidade que cada sujeito tem de colocar-se no lugar do outro. Desenvolver a capacidade de assumir a atitude do outro, o papel social do 'outro generalizado', implica, de algum modo, no desenvolvimento da capacidade de articular ações cooperativas desde o interior das relações sociais. Mead não concebe o sujeito isolado, como um self ilhado. Ao contrário disso, concebe-o como um self em constante relação, individualizado porque socializado.

O pré-requisito da participação e da cooperação dos sujeitos no todo social pressupõe o desenvolvimento progressivo do self. Para isso, a interação, a comunicação, o aumento da capacidade racional, o descentramento do eu, o agir ético e a participação democrática são indispensáveis. As instituições educacionais, enquanto espaços de aprendizagem e de socialização, podem contribuir significativamente nesse processo, para que os sujeitos desenvolvam competência de viver em comunidade e progridam para estágios mais avançados de individuação e de sociabilidade. Essa contribuição refere-se, primariamente, a considerar que a interação, o encontro com o outro, as experiências de coordenação das ações e o confronto com o diferente e o diverso consistem, também, em conteúdos fundamentais à estruturação dos currículos em todos os níveis de ensino. 
1 "O homem sem um impulso generoso é anormal e repugnante" (tradução nossa).

2 George Herbert Mead, autor americano do movimento pragmatista, radicado na Universidade de Chicago, viveu entre os anos de 1863 e 1937.

3 Vale uma referência a algumas obras e autores, em língua portuguesa, que se dedicaram à introdução de G. H. Mead no meio acadêmico brasileiro: Odair Sass (2004); Filipe Carreira da Silva (2009); Claudio Almir Dalbosco (2010); Cledes Antonio Casagrande (2014 e 2016). Um exemplo do desconhecimento de G. H. Mead, no Brasil, é a inexistência de referências ou citações na coletânea "Pragmatismos, pragmáticas e produção de subjetividade” (ARRUDA; BEZERRA JR.; TEDESCO, 2008), dedicada a analisar, de forma panorâmica, o que é o pragmatismo.

4 Quando falamos dos escritos de G. H. Mead devemos levar em consideração que nos referimos aos seus artigos publicados e às transcrições das suas aulas, organizadas e publicadas por seus alunos, visto que ele não escreveu nenhum livro. A principal obra que temos acesso é Mind, self, and society (MEAD, 1967), também traduzida ao espanhol (MEAD, 1973). No Brasil, essa obra foi traduzida com o título de Mente, self e sociedade e atribuída a Charles Morris, o organizador; por isso não iremos referenciá-la aqui. Além disso, destacam-se as seguintes coletâneas de textos: Selected writings (MEAD, 1981); On social psychology (MEAD, 1984); The philosophy of the present (MEAD, 2002); Play, school, and society (MEAD, 2006); The philosophy of education (MEAD, 2008); Escritos politicos y filosóficos (MEAD, 2009).

5 O tema da formação do self a partir da matriz teórica de G. H. Mead já foi por nós abordado anteriormente (CASAGRANDE, 2014 e 2016). Sobre o mesmo assunto, indicamos também conferir o artigo escrito em conjunto com a professora Nadja Hermann (CASAGRANDE; HERMANN, 2017). Já as possíveis implicações dos processos educacionais que restringem os processos de socialização, especialmente as experiências interativas e o contato com o outro, na perspectiva apontada por Mead, foi tema do artigo "Formação e homeschooling: controvérsias" (CASAGRANDE; HERMANN, 2020).

6 Para auxiliar na compreensão dos textos de Mead, indicamos, entre parêntese, sempre que julgamos necessário, a versão original dos seguintes termos: brincar (play); jogar (game); eu (I); mim (me). Em relação à tradução do termo self, decidimos manter a grafia original em inglês por entendermos que a tradução por 'pessoa' não corresponde ao significado mais adequado; uma tradução aceitável em português poderia ser 'si mesmo'.

7 Esse duplo processo podemos denominar, tecnicamente, de uma homologia ontofilogenética. Ou seja, ontogenia e filogenia são processos correlacionados e mutuamente dependentes. Sobre esse assunto, recomendamos o livro de Silva (2009, p. 161-183), no qual ele analisa a psicologia social de Mead e aprofunda os conceitos de ontogenia e filogenia.

\section{Referências}

ARRUDA, Arthur; BEZERRA JR., Benilton; TEDESCO, Sílvia (org.). Pragmatismos, pragmáticas e produção de subjetividades. Rio de Janeiro: Garamond, 2008.

BIESTA, G. J. J. Mead, intersubjectivity, and education: the early writings. Studies in Philosophy and Education, Springer Netherlands, v. 17, n. 2-3, p. 73-99, Jun. 1998. Disponível em: http://www.metapress.com/content/p2437140t885hh20/fulltext.pdf. Acesso em: 08 maio 2010.

BIESTA, G. J. J. Radical Intersubjectivity: reflections on the "different" foundation of education. Studies in Philosophy and Education, Dordrecht, v. 18, n. 4, p. 203-220, Jul. 1999a. Disponível em: http://www.metapress.com/content/2rwhm9g9nqgy/?p=7ff19284626049d28e23b7c35523afea\&pi=0. Acesso em: 08 maio 2010. 
BIESTA, G. J. J. Redefining the subject, redefining the social, reconsidering education: George Herbert Mead's course on Philosophy of Education at the University of Chicago. Educational Theory, Illinois, v. 49, n. 4, p. 475-492, 1999b. Disponível em: http://onlinelibrary.wiley.com/doi/10.1111/j.1741-5446.1999.00475.x/abstract. Acesso em: 02 mar. 2012.

BIESTA, G. J. J.; TRÖHLER, D. George Herbert Mead and the development of a social conception of education. In: MEAD, George Herbert. The philosophy of education. Boulder, CO: Paradigm Publishers, 2008. p. 01-16.

CASAGRANDE, Cledes Antonio. G. H. Mead \& a educação. Belo Horizonte: Autêntica Editora, 2014.

CASAGRANDE, Cledes Antonio. Interacionismo simbólico, formação do self e educação: uma aproximação ao pensamento de G. H. Mead. Educação e Filosofia, v. 30, n. 59, p. 375403, jan./jun. 2016. DOI: https://doi.org/10.14393/REVEDFIL.issn.0102-6801.v30n59a2016-p375a403.

CASAGRANDE, Cledes Antonio; HERMANN, Nadja. Identidade do eu em contextos plurais: desafios da formação. Proposições, v. 28, Suppl. 1, p. 39-62, 2017. DOI: https://doi. org/10.1590/1980-6248-2016-0046.

CASAGRANDE, Cledes Antonio; HERMANN, Nadja. Formação e homeschooling: controvérsias. Práxis Educativa, Ponta Grossa, v. 15, e2014789, p. 1-16, 2020. DOI: https://doi. org/10.5212/PraxEduc.v.15.14789.032.

DALBOSCO, Cláudio Almir. Pragmatismo, teoria crítica e educação: ação pedagógica como mediação de significados. Campinas, SP: Autores Associados, 2010.

HABERMAS, Jürgen. Obras escolhidas: fundamentação linguística da sociologia. Lisboa: Edições 70, 2010. v. 1.

HONNETH, Axel. Luta por reconhecimento: a gramática moral dos conflitos sociais. São Paulo: Editora 34, 2003.

HONNETH, Axel. Crítica del agravio moral: patologías de la sociedad contemporánea. Buenos Aires: Fondo de Cultura Económica; Universidad Autónoma Metropolitana, 2009.

KAMINSKY, Gregorio. Estudio preliminar. In: MEAD, George Herbert. Escritos políticos y filosóficos. Buenos Aires: Fondo de Cultura Económica, 2009. p. 9-33.

MEAD, George Herbert. Mind, self, and society: from the standpoint of a social behaviorist. Chicago: The University of Chicago Press, 1967.

MEAD, George Herbert. Espíritu, persona y sociedad: desde el punto de vista del conductismo social. Barcelona: Paidós, 1973.

MEAD, George Herbert. Selected writings. Chicago: The University of Chicago Press, 1981.

MEAD, George Herbert. On social psychology. Chicago: The University of Chicago Press, 1984.

MEAD, George Herbert. The philosophy of the present. Amherst: Prometheus, 2002.

MEAD, George Herbert. Play, school, and society. New York: Peter Lang Publishing, 2006. 
MEAD, George Herbert. The philosophy of education. Boulder, CO: Paradigm Publishers, 2008.

MEAD, George Herbert. Escritos políticos y filosóficos. Buenos Aires: Fondo de Cultura Económica, 2009.

RECK, Andrew J. Editor's indroduction. In: MEAD, George Herbert. Selected writings. Chicago: The University of Chicago Press, 1981. p. 13-62.

SASS, Odair. Crítica da razão solitária: a psicologia social segundo George Herbert Mead. Bragança Paulista: Editora Universitária São Francisco, 2004.

SILVA, Filipe Carreira da. Em diálogo com os tempos modernos: o pensamento político e social de G. H. Mead. Rio de Janeiro: Tempo Brasileiro, 2009.

TUGENDHAT, Ernst. Autoconciencia y autodeterminación: una interpretación lingüístico-analítica. Madrid: Fondo de Cultura Económica, 1993.

YNCERA, Ignacio Sánchez de La. Interdependencia y comunicación. Notas para leer a G. H. Mead. Revista Española de Investigaciones Sociológicas, Madrid, n. 55, p. 133-164, 1991.

YNCERA, Ignacio Sánchez de La. La mirada reflexiva de G. H. Mead: sobre la socialidad y la comunicación. 2. ed. Madrid: Centro de Investigaciones Sociológicas, 1994. 